\title{
Application Research of "Field" Theory in the Problem of Colleges and Universities Innovation Team Aggregation
}

\author{
HongJing Liang $\left(\mathbb{D},{ }^{1}\right.$ JinSheng Liu, ${ }^{2}$ Rong Wang $\mathbb{D}^{1},{ }^{1}$ YaQin Song, ${ }^{1}$ and YuanYuan Zhou ${ }^{1}$ \\ ${ }^{1}$ School of Economics and Management, Nanjing Institute of Technology, Nanjing, Jiangsu 211167, China \\ ${ }^{2}$ School of Mathematics and Physics, Nanjing Institute of Technology, Nanjing, Jiangsu 211167, China \\ Correspondence should be addressed to HongJing Liang; nanjinglhjs@163.com
}

Received 3 December 2019; Revised 1 March 2020; Accepted 6 March 2020; Published 31 March 2020

Academic Editor: Anna Vila

Copyright (c) 2020 HongJing Liang et al. This is an open access article distributed under the Creative Commons Attribution License, which permits unrestricted use, distribution, and reproduction in any medium, provided the original work is properly cited.

\begin{abstract}
Based on the field theory in physics, the thesis applies model construction and other methods to apply the research on the agglomeration problem of colleges' and universities' innovation teams and constructs the growth field model of colleges' and universities' innovation teams. The conclusions show that the "growth field" of the colleges' and universities' innovation team is composed of two elements: "hidden growth factor" and "dominant growth factor," which have the directional and force acting; if the growth force is more powerful than the resistance, the team growth will move forward along the growth path; if the resultant force is greater than the power, it will enter the recession or be stagnant in advance. The growth path is different in the magnitude and direction of the force at each stage, and the growth path of the individual members of the team and the team as a whole is also different; there is agglomeration in the growth field, and the excellent academic leaders are particularly important. It is a process in which the field forces overlap each other, which will form a situation of continuous agglomeration and a virtuous cycle of interaction and find out the ways to integrate and enhance the ability of colleges' and universities' innovation teams under the field effect, in order to achieve the goal of attracting talents to join, optimizing and integrating within the team, improving the overall ability of the team, and increasing outputs.
\end{abstract}

\section{Introduction}

The innovation ability of colleges and universities is the most direct and powerful embodiment of the level of national innovation capability. To a certain extent, it determines the level of innovation capability of the country. More and more innovations are produced in the form of innovative teams. The colleges' and universities' innovation team shoulders a large part of the important mission of promoting national science and technology innovation. Therefore, it is a great significance to mobilize and stimulate the innovative motives and personal potential of innovative team members to realize the value-added effect of " $1+1>2$ " in academic research and technological innovation.

In recent decades, great changes have taken place in China's scientific research environment. The number of colleges' and universities' innovation teams has increased rapidly; from the initial innovation team funded by the state, local governments have begun to attach importance to the construction of innovation teams in colleges and universities. Now, more and more colleges and universities have begun to prepare their own innovation teams. From the initial dozen innovation teams funded by the state to thousands of innovation teams funded by the local government and universities, the teams are constantly growing. China's emphasis on innovation teams in universities has also increased year by year. Zou and Wei [1] studied the status of the innovation team and found that, in the basic research part, universities have gradually become the main force of original research. While the state has increased investment in scientific research and development and innovation in universities, it has also increased its support for outstanding scientific research teams in universities and even increased funding for research in innovative scientific 
research teams in universities. Fu [2] studied the policies of the central government of China on scientific research funding in colleges and universities since the reform and opening up. The Ministry of Education officially launched the Changjiang Scholars and Innovation Team Program in 2004, which aims to give full play to the advantages of talents and groups to promote the construction of high-level universities and key disciplines. In 2005, the National Natural Science Foundation of China established the Scientific Research Fund for Innovative Research Groups in order to steadily support cutting-edge research in basic sciences and to cultivate and create innovative talents and groups. In 2006, the National Medium- and Long-Term Scientific and Technological Development Planning Outline (2006-2020) was promulgated, and "through various efforts, the proportion of China's total research and development investment as a percentage of GDP has been increasing year by year, and by 2010 reached $2 \%$ per year and more than $2.5 \%$ by 2020." At the same time, the following was also pointed out: "universities are an important base for cultivating highlevel innovative talents in China. They are one of the main forces in China's basic research and original innovation in high-tech fields. They are the new forces for solving major scientific and technological problems in the national economy, realizing technology transfer, and transforming achievements." Although the sources of scientific research funding for Chinese universities are mainly the government, enterprises, and other social forces, the government should always be the main body of scientific research funding for universities. Universities and colleges in various provinces and cities have also formulated corresponding policies and implementation plans for the construction and management of scientific research and innovation teams in line with the characteristics of each university, such as superior talent introduction and talent flow strategies, excellent talent settlement policies, settling in fees, research start-up funds, and infrastructure support. At the same time, in colleges and universities, interdisciplinary scientific research teams are increasingly highlighting their important role. These teams are based on the complementary advantages of the disciplines, using multidisciplinary and multiprofessional crosscutting to overcome major interdisciplinary issues. Major universities also attach great importance to outstanding academic leaders and outstanding team members and provide great support and funding.

Combined with the actual situation of the colleges' and universities' innovation team in China, related problems have gradually emerged. Many scholars have studied related issues; Fu [2], Zhu [3], Liang et al. [4], and others studied the current situation, problems, and incentive mechanism of China's innovation team. It can be summarized as follows: first, there is a lack of long-term and reasonable planning and scientific and sound mechanism in colleges and universities. The most important thing is the lack of long-term and reasonable planning, which is mainly reflected in the instability of team members and the attraction and selection of excellent academic leaders. The lack of scientific and sound internal mechanism in colleges and universities is mainly reflected in the division of labor among team members, internal resource allocation, internal assessment, and incentives. Second, The change of social (in this case refers to the external environment other than the government, such as the overall market, research institutes, enterprises, intermediaries or civil organizations, and other entities involved in the allocation of scientific and technological resources) opinion orientation has a great influence on the resource allocation and outcome output of the colleges' and universities' innovation teams. In particular, the existence of "Matthew effect" will lead to inequity and inefficiency in resource allocation, which will inhibit the training and development of many emerging teams and excellent potential talents to a certain extent. Third, the government urgently needs to establish a more scientific and reasonable evaluation and supervision mechanism in the construction of the colleges' and universities' innovation teams: this is because the government, as the highest decision-maker and resource planner of macrocontrol, has a great guiding role in the construction of the colleges' and universities' innovation teams. If the government lacks support for team building, many research teams will not function properly or affect their output efficiency. Conversely, if some research projects are too supportive but there is no corresponding evaluation and supervision mechanism for supervision in the later stage, it will also result in waste of resources and certain social and market misleading. Fourth, the colleges and universities innovation teams lack sustained and effective benign incentives in their different growth cycles: the various incentives required for different growth cycles are different and therefore require different incentives to promote their growth. Many innovation teams lack this understanding and generally adopt the same incentive strategy, which cannot effectively stimulate the members of different growth cycles and the entire team to grow better and faster, and there are certain resources waste and unsatisfactory incentive effects. The existence of these problems directly affects the overall output of the innovation teams in China's colleges and universities and has a great impact on China's ability to innovate. Therefore, it is necessary to find a suitable way to improve the overall ability of colleges and universities innovation teams and improve the scientific and technological output.

In view of this background, this paper applies the field theory in physics to the research of colleges' and universities' innovation teams and puts forward the growth field of college innovation teams. The point of view of field theory is that the field will embody a force called "field force," which has an effect on all the related substances. This paper regards the internal and external elements in the process of innovation team growth as internal and external forces in the field and regards the implicit relationship between these elements as the field force line. This paper studies the growth path of colleges' and universities' innovation team members under the influence of various elements and the agglomeration of colleges' and universities' innovation team under the influence of field effect. On the basis of this research, this paper puts forward relevant measures to enhance the field of colleges' and universities' innovation team growth and then makes the individual and the team grow together, thereby 
improving the overall innovation level of the society, for example, improving and perfecting the system and policy of talent introduction, implementing incentive measures at different stages, paying attention to the role of organizational commitment, and increasing funding and education investment to provide sufficient support for team innovation.

Sundstorm et al. [5], Zhang [6], and many scholars studied the team and field theory. But in literature reading and literature retrieval, after inputting "the field theory" and the key words "university innovation team" at the same time, the articles retrieved are almost nothing, which shows that, at present, there are few studies on the application of field theory to colleges' and universities' innovation teams at home and abroad. It is very important to apply field theory to research colleges' and universities' innovation teams. On the one hand, it can enrich the research in this field. Under the background of global innovation, using field theory to study the improvement of innovation ability of innovation teams in Chinese universities can complement and improve the existing theoretical foundation. On the other hand, it is of great practical significance to promote the overall ability of innovation teams in colleges and universities and then to improve the national innovation ability.

The marginal contribution of this paper is embodied in the following: firstly, the "growth field" model of the colleges' and universities' innovation team is constructed. The "growth field" of the innovation team of colleges and universities is composed of two elements: "implicit growth factors" and "dominant growth factors," which have the role of directionality and strength. Secondly, growth path in the growth field is studied, the growth path is different in the magnitude and direction of the force at each stage, and the growth path of the individual team members and the team as a whole is also different. Thirdly, the phenomenon of colleges' and universities' innovation team agglomeration is studied under the effect of "field." There is a phenomenon of agglomeration in the growth field, and excellent academic leaders are particularly important. This phenomenon is a process in which the field forces overlap each other, which will form a situation of continuous agglomeration and a virtuous cycle of interaction. Fourthly, the integration and improvement of the ability of colleges' and universities' innovation teams are studied under the field effect, in order to achieve the goal of attracting talents to join, optimizing and integrating within the team, improving the overall ability of the team, and increasing output.

\section{Literature Review}

2.1. Innovation Team. Robbins [7] defined the concept of the team in his book. He also believed that the key is to find ways to give full play to the advantages of the team and achieve high performance and high output in team research. Sundstorm et al. [5] believed that team performance is composed of the total output of various outputs, the team's behavioral and psychological impact on individual members, and the increase in overall work effectiveness. Hoegl and Gemuenden [8] believed that team performance is the ability to meet the team's target quality, team target cost, and duration constraints. Drach-Zahavy and Freund [9], based on previous research, added learning organization, work skill reflection, problem discussion, and experimental behavior, which increased the measurement scope of team performance, and then comprehensively analyzed the team performance level. Paker [10] believed that an effective team must include the following characteristics: clear goals, informal atmosphere, participation, listening, etc. Rey-Rocha et al. [11] analyzed the influence of stable and unstable teams on the individual scientific research achievements of scientists; they believed that the researchers who belong to stable teams have more achievements than those who belong to loose teams, and both of them have more achievements than those who do not form teams. Nijstad [12] mainly expounds team creativity and innovation.

The "Support Method for the Development of Changjiang Scholars and Innovation Teams" issued by the Ministry of Education clearly states that the innovation team should be composed of a small number of scientific researchers based on key laboratories, engineering centers, or related key disciplines. The members have mutual professional skills and common research goals; they have long-term cooperation and strong spirit of teamwork. Wang and Tian [13] believed that the research and innovation teams of colleges and universities are a group of researchers who are complementary in knowledge and skills and who are based on scientific and technological research and development. They have common research goals and research tasks. Zhang et al. [14] believed that the research teams are organizations composed of researchers in interdisciplinary fields with complementary knowledge and skills for the purpose of academic research and scientific and technological development.

Zhou [15] found some problems in the operation mechanism of the team. Zhang [16] defined the concept of the research team, discussed the types and organizational characteristics of the research team, and obtained some problems in the research team of the university and proposed solutions.

Yuan [17] believed that we should start with the value system of incentives and the improvement of the quality of the team and constantly adjust the incentive mechanism to promote the development of innovative teams in colleges and universities. Zhang [18] pointed out that the innovative ability of scientific research and innovation team refers to a comprehensive ability to integrate the creativity of team members with various resources under the leadership of academic leaders and ultimately enable the whole team to have strong innovative thinking and creative ability so as to achieve more innovative results.

The abovementioned literatures are mainly studied from the concept of the team, the concept of university innovation team, the problems existing in the innovation team of colleges and universities, and the incentive measures. It has great theoretical and practical value. However, the activities of innovation teams in colleges and universities are a complex system, which needs to be further integrated by adding new methods on the basis of the original research. 
2.2. Agglomeration. As early as the 19th century, industrial agglomeration has become the focus of attention of many scholars. Clark [19] classified the industry in the 19th century; he found that the regional industrial structure (mainly divided into the first two or three industries) is an important factor to attract talents. Sahin [20] found that the investment in science and technology, internal and external environmental factors, and talent security policy factors all affect the scale of talent agglomeration. Giannetti [21] believed that, in order to reduce production costs and create economies of scale, companies should work in various ways to bring together workers with different skills and abilities. Venkatesh and Gerhard [22] analyzed how to achieve effective talent concentration. He believed that the regional institutional environment is the key to the effect of technological talent concentration. Romer [23] thought that the government is an important factor influencing the effect of scientific and technological talents agglomeration. Freeman [24] thought that the main factor affecting the agglomeration effect of scientific and technological talents is technological environment. Different technological levels will produce different agglomeration effects.

Chinese scholars studied the concept, connotation, and interaction of talent agglomeration from different perspectives. Niu [25] and others believed that, from an economic point of view, the concentration of production factors and other related activities within a certain space will form a certain scale. The formation of this scale will enable these production factors and economic activities to achieve a very high efficiency; this efficiency is not achievable in a decentralized state, which is the "aggregation effect." Wang [26] believed that policy factors are more important. In fact, this also reflects the complexity and multifaceted nature of the talent gathering system research. Chen [27] believed that, in order to achieve the positive effects of talent agglomeration, it is necessary to give full play to the incentive role of the market and the guiding role of the government to attract and retain outstanding talents. Wang [28] proposed the "Trinity" talent agglomeration model, giving full play to the role of the government, the market, and universities and research institutions.

The abovementioned literatures studied the concept of talent agglomeration, influencing factors, and relevant measures of talent agglomeration. They focus more on static analysis of talent agglomeration, but there is lack of empirical research on interaction relationship and multidisciplinary integration research.

2.3. Field Theory. Famous social psychologist Lewin puts forward the famous "field theory," which was the first time that physical concepts such as field, force, and vector were used to describe people's various behaviors in their surrounding environment and space. In the 1880s, Ravenstein [29] first applied this physical model to social science research to study the problem of gravity model migration for population space. In 1931, Reilly [30] proposed a retail gravity model. Smith et al. [31] are typical scholars who study geography by analogy of gravitational formulas.
Chinese scholars have more and more research studies on the field, including tangible and intangible field. Tangible field includes Wang [32], ecological field; Dong and Xie [33], resource field; and Zhang et al. [34], tourist field. Intangible field includes Zhang [6], information field; Xu et al. [35], knowledge field; and Chen et al. [36], water resources demand field.

Combined with the abovementioned analysis, the application of field theory in various fields has been studied. For example, Nijstad [12], Niu [25], Ma [37], and others studied the problems of innovation teams and agglomeration in universities and field. But, under the field theory, the agglomeration of innovation teams in universities is almost nothing. This paper will focus on this.

\section{The Application of "Field" Theory}

3.1. Field Theory Basis. Classical electromagnetic theory shows that there is an interaction force between charge and charge, and the magnitude of the force is proportional to the product of the charge quantity and inversely proportional to the square of the distance. Coulomb's law is an experimental law. By studying the relationship between the magnitude and direction of the interaction force between two charged particles (point charges) in vacuum and the magnitude and distance of point charges, we have the following:

$$
\mathbf{F}_{12}=k \frac{Q_{1} Q_{2}}{\mathbf{r}_{12}^{3}} \mathbf{r}_{12},
$$

where $q_{1}$ and $q_{2}$ are the electric quantities of two point charges, $\mathbf{r}_{12}$ is the distance between them, $\mathbf{F}_{12}$ means that the electric charge $q_{2}$ is subjected to the electrostatic force of $q_{1}$, and $\mathbf{r}_{12}$ is the vector diameter from $q_{1}$ to $q_{2} . k$ is a constant and its value is $\left(1 / 4 \pi \varepsilon_{0}\right), \varepsilon_{0}$ is a vacuum dielectric constant. In the International System of Units (SI), the unit of electricity is Coulomb $(\mathrm{C})$, the unit of $\mathbf{r}$ is meter $(\mathrm{m})$, and the unit of force is Newton $\left(\mathrm{kg} \cdot \mathrm{ms}^{-2}\right)$. It can be concluded from formula (1) that if $Q_{1}$ and $Q_{2}$ are identical charges, $\mathbf{F}_{12}$ and $\mathbf{r}_{12}$ are identical, indicating that the two charges repel each other; when $Q_{1}$ and $Q_{2}$ are heterogeneous charges, $\mathbf{F}_{12}$ and $\mathbf{r}_{12}$ are in opposite direction, indicating that the two charges attract each other.

Electric field is a field with sources. In order to study the nature of electric field, we need to introduce a source charge $+Q$ and a test charge $q_{0}$ (linearity and electric quantity are small enough) into the electric field. The electric field force $\mathbf{F}$ of $q_{0}$ can be obtained by formula (1), and the ratio of $\mathbf{F}$ to $q_{0}$ is only related to its spatial position; it is defined as electric field strength $\mathbf{E}$; that is,

$$
\mathbf{E}=\frac{\mathbf{F}}{q_{0}}=k \frac{\mathrm{Q}}{r^{3}} \mathbf{r} .
$$

In formula (2), $\mathbf{r}$ is the vector diameter from the source charge to the observation point. If the field source is composed of $n$ discrete point charges, the electric field intensity generated by the source is as follows: 


$$
\mathbf{E}=k \sum_{i=1}^{n} \frac{q_{i}}{\mathbf{r}_{i}^{3}} \mathbf{r}_{i}
$$

In formula (3), $\mathbf{r}_{i}$ is the vector diameter from the ist point charge to the observation point.

In Cartesian coordinates, the formula for calculating the electric field strength of point charge $Q$ at point $A$ in space can be written as follows:

$$
|\mathbf{E}|=\frac{k Q_{1}}{\left(x-x_{1}\right)^{2}+\left(y-y_{1}\right)^{2}+\left(z-z_{1}\right)^{2}} .
$$

In formula (4), $|\mathrm{E}|$ is the magnitude of the electric field strength of a charge at a point $A(x, y, z)$ in space, $Q_{1}$ is the amount of charge of that charge, and $\left(x_{1}, y_{1}, z_{1}\right)$ is the space coordinate of the charge. If the source charge is composed of multiple point charges, the electric field strength at a point $A$ is the superposition of the electric field strength of all charges here, and the calculation formula can be written as follows:

$$
\mathbf{E}=\sum_{i=1}^{N} k Q_{i}\left[\frac{\left(x-x_{i}\right)}{\mathbf{r}_{i}^{3}} i+\frac{\left(y-y_{i}\right)}{\mathbf{r}_{i}^{3}} j+\frac{\left(z-z_{i}\right)}{\mathbf{r}_{i}^{3}} k\right] .
$$

Among them, $Q_{i}$ is the amount of charge of the $i$ th charge, and its coordinates are $\left(x_{i}, y_{i}, z_{i}\right)$; $\mathbf{r}_{i}=\sqrt{\left(x-x_{i}\right)^{2}+\left(y-y_{i}\right)^{2}+\left(z-z_{i}\right)^{2}}$ is the distance from point $A$ to the $i$ th charge. $i, j$, and $k$ are unit vectors in three directions of the rectangular coordinate system.

Gauss's theorem shows that the flux $\oiint_{S} \mathbf{E} \cdot \mathrm{d} \mathbf{S}$ of electric field strength (the number of electric field lines) through any closed surface is proportional to the total amount of charge surrounded by the surface. Its form can be expressed as

$$
\begin{array}{r}
\oiint_{\mathbf{S}} \mathbf{E} \cdot \mathrm{d} \mathbf{S}=\frac{Q}{\varepsilon_{0}}, \\
\text { or } \nabla \cdot \mathbf{E}=\frac{\rho}{\varepsilon_{0}} .
\end{array}
$$

Among them, $\nabla \cdot \mathbf{E}$ represents the divergence of the vector field $\mathbf{E}, \mathbf{S}$ represents the closed plane, and $\rho$ represents the charge density in the $\mathbf{S}$ space. The core idea is that the electric field is a field with sources. When the quantity of electricity is known, the electric field strength distribution in space can be easily obtained by using this formula.

Ampere circuital theorem shows that the line integral of electric field strength along any closed path is zero in an electrostatic field:

$$
\begin{aligned}
& \oint_{L} \mathbf{E} \cdot \mathrm{d} \mathbf{l}=0, \\
& \text { or } \nabla \times \mathbf{E}=0 .
\end{aligned}
$$

Among them, $\nabla \times \mathbf{E}$ is the Curl of vector field $\mathbf{E} . \mathbf{1}$ represents the closed path. Ampere circuital theorem shows that the electric field is an irrotational field.

3.2. Field Theory Application. Zhang [6] introduced the concept of informativeness into the research, and the charge analogy became the information point of the smallest unit of information system interaction. Coulomb's law is used here to describe the interaction of information points and proposes a formula for the information field strength vector $\mathbf{E}$ at a point in space that is subjected to a single information point (here denoted by $q$ ):

$$
\mathbf{E}=k \frac{q}{\mathbf{r}^{3}} \mathbf{r}
$$

where $\mathbf{E}$ is used to represent the strength of the information field, $k$ is a proportional coefficient, $q$ is the information quantity of a certain information point, and $\mathbf{r}$ is the vector diameter from a certain information point to a point in space. If there are $i$ information points in the information field, it can be concluded that the field strength of the information field received by a certain point in the information field is superimposed by the vector of the information field strength of each information point at this point:

$$
\mathbf{E}=k \sum_{i=1}^{n} \frac{q_{i}}{\mathbf{r}_{i}^{3}} \mathbf{r}_{i} .
$$

Xu et al. [35] and others proposed the concept of the total amount of knowledge resources on the premise that the distribution of knowledge in time and space is not uniform. The concept of knowledge radiation intensity is put forward. On this basis, five characteristics of knowledge field are summarized, and a quantitative calculation is carried out in the Yangtze River Delta region as an example:

$$
Q=\alpha_{1} Q_{1}+\alpha_{2} Q_{2}+\alpha_{3} Q_{3}+\alpha_{4} Q_{4}+\alpha_{5} Q_{5} .
$$

In the formula, $\alpha_{i}(i=1,2,3,4,5)$ is the weight of the component of each knowledge resource; $Q_{1}$ to $Q_{5}$ represent the knowledge stock, knowledge level, knowledge flow, knowledge structure, and knowledge distribution, respectively.

In this study, the source of knowledge is the emitter of knowledge, and the knowledge sink is the receiver of knowledge radiation. Based on the Gauss theorem, the knowledge radiation intensity of a point in space is considered as a vector. The field strength of the knowledge field can be calculated by the following formula:

$$
\mathbf{E}=k \frac{q}{\mathbf{r}^{3}} \mathbf{r},
$$

where $\mathbf{E}$ is a vector representing the knowledge radiation intensity of the knowledge field; $q$ represents the total amount of knowledge resources; $k$ represents the knowledge absorption capacity coefficient; $r$ represents the vector distance between the knowledge source and the knowledge sink.

Chen and others [36] proposed the theory of "water demand field." According to Coulomb's law, the formula for calculating the strength of water field in plane is as follows:

$$
\mathbf{E}_{W}=\frac{Q}{2 \pi \mathbf{r} \varepsilon_{W}} \frac{k_{w} Q}{\mathbf{r}}
$$

In the formula, $\mathbf{E}_{W}$ is the field strength of the "water field" at a point in the "water field"; $\mathbf{E}=\left(k Q / \mathbf{r}^{2}\right)$ represents the "water field" constant; $Q$ stands for "water load," which is 
the water demand of the city in which it is located; $\mathbf{r}$ represents the distance from any point to the "water charge" $Q$.

The various field models described above are closely related to Coulomb's law at the source.

\section{Empirical Research}

4.1. The Composition of the Growth Field of University Innovation Team. The "growth field" of innovation teams is composed of two elements: "hidden growth elements" and "dominant growth elements"; they are directional and forceful. Xing [38] studied growth elements in paper. In the growth field of university innovation team, the "dominant growth elements" can be seen as the internal and external influence element of the growth of the innovation team, while the "hidden growth elements" can be seen as the intangible effect of the interaction between these key elements. The details are as follows.

Tang et al. [39] studied the growth mechanism of smalland medium-sized technological enterprises. In this paper, the intrinsic growth elements of colleges and universities innovation teams mainly refer to the qualities and abilities of the innovation team members. The intrinsic field of action refers to the intrinsic elements that act on the growth of talents together and the interaction between them, and the internal force of the field is determined by these intrinsic growth elements; the force line of internal force field refers to an intangible relationship, which is the interaction force that links these closely related internal growth elements together, and is a hidden growth element. At the same time, the influence of external environment on the growth of innovation team is also very important. The external elements of the growth of innovation team refer to the external elements that directly or indirectly affect the innovation team. The external action field is composed of the environmental elements outside the team and the mutual relationship between the elements; the external force of the field is composed of these external growth elements; the external force field line is also an intangible relationship, which is external to these teams. The interaction forces that are closely related to growth elements are also a hidden growth element. The force of these recessive growth elements is mainly expressed by the correlation between the elements of dominant growth elements, as shown in Figure 1.

Based on the research of various tangible and intangible field theories and innovation teams by scholars involved in the abovementioned literature review, this paper proposes "growth field" of colleges and universities innovation team. In the "growth field" of the abovementioned colleges' and universities' innovation team, the field source is the core, which is formed by the internal elements of academic leaders and members' knowledge, skills, and innovation and so on, while the external elements indirectly affect the growth process of university innovation team by linking with the internal elements. The field strength of growth field is

$$
\mathbf{E}=\frac{k Q}{\mathbf{r}^{2}}
$$

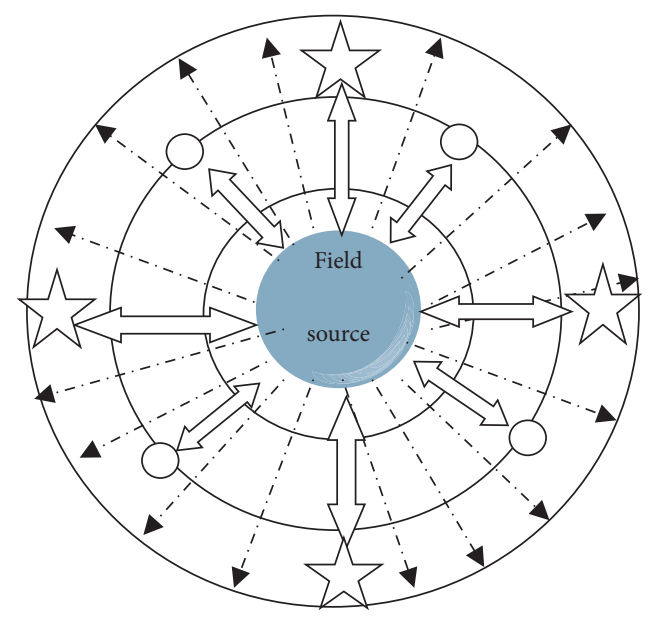

\footnotetext{
h Representing external forces (representative: macroenvironment, industry living environment, unit environment)

- Representing internal forces (representative: knowledge skills, comprehensive skills, etc.)

$\rightarrow$ Representing the direction of the growth field

$\Leftrightarrow$ Representing the influence of internal and external forces on the field
}

FIgURE 1: Growth field of colleges' and universities' innovation team.

Among them, "E" is the radiation intensity of the growth field, which is a vector; " $k$ " is the environmental coefficient of the growth field (value is greater than 0 ), $k=1$ is the simple environment, $k<1$ is a complex environment, and the more complex the environment, the smaller the $k$ value. Here, it is assumed that the innovation team is in a relatively simple environment; that is, $k$ is close to 1 ; " $Q$ " is the total amount of resources for the growth field; " $Q$ " stands for the knowledge and skill and output of existing members, especially the strength and influence of academic leaders, existing research infrastructure and funding, knowledge sharing platforms, the quantity and quality of innovation achievements, the cooperation between university teams and high-tech enterprises, etc. It can be expressed by the following formula:

$$
Q=p_{1} Q_{1}+p_{2} Q_{2}+p_{3} Q_{3}+p_{4} Q_{4}+\cdots+p_{n} Q_{n} \text {. }
$$

$p_{n}(n=1,2,3,4, \ldots, n)$ is the weight of the components of growing field source; $Q_{n}(n=1,2,3,4, \ldots, n)$ is the constituent element of growing field source. The weight can be determined by relevant experts according to the actual situation. "r" refers to the "distance" between on-site sources and offsite talents or teams; it can be considered as the result of the interaction of internal and external forces. If the result of interaction between internal and external forces is positive, it is the power of innovation team, and it can increase the field strength and attract talents from outside. On the contrary, it will become a resistance to the growth of innovation teams in colleges and universities; the field strength will be weakened. The resistance is reflected in some situations that are not conducive to the growth of the innovation team in colleges and universities or the changes of external policy support, which causes some obstacles to the growth of the innovation team in colleges and universities. " $\mathbf{r}$ " is mainly measured by 
two aspects. On the one hand, it measures internal forces, which are internal factors that affect team development, including the team members' knowledge structure, age level, skill level, scientific research funds, scientific research output and awards, cooperation platform with high-tech enterprises, and team influence. On the other hand, it measures external forces that affect team development, including policy support trend, national development direction, internal management focus of colleges and universities, technical reform, and development trend. These can be obtained through research, expert review, and big data analysis.

The growth of the innovation team is mainly measured by the number and quality of excellent team members within the team, the overall innovation ability of the team, the accumulated experience and skills of the team, the quantity and quality of scientific research results, the quantity and quality of the awards, talent training, the transformation and application of results, etc. The internal and external forces that influence the growth of the innovation team in colleges and universities can be regarded as the internal and external growth elements. Among the internal forces, the representatives are the combined force formed by the members' knowledge and skill level, comprehensive ability, physical and mental health, emotional intelligence, learning ability, age, and other internal factors that affect team members' growth. Among the external forces, the representatives are the combined force formed by the policy environment, living environment, internal work and research environment of universities, management systems and development plans in various places, etc.

The internal and external forces in the growth field act together on the growth of innovation teams in colleges and universities. Some forces in the field, especially external forces, are greatly affected by external objective conditions. At this time, it is difficult for individual members or the whole team to influence and change the magnitude and direction of such forces, and they can only be passively accepted. These forces have both power and resistance. This means that the growth path of colleges and universities innovation teams is a tortuous path rather than smooth sailing under the influence of various forces.

\subsection{The Formation of Growth Path in the Growth "Field".} Through literature and investigations, in an ideal state, the growth path of innovation teams in universities is similar to the growth path of talents, Wang [40] described the law of talent growth and path, and it is similar to the normal distribution. Combined with the growth path of talent growth [40], this paper puts forward the growth path of the colleges and universities innovation team. The horizontal axis represents the "development stage" of innovation team, and the vertical axis represents the "output" of innovation team. By measuring the development stage and team output, we can get the realistic development path of university innovation team and judge when and what external supports are needed. The growth path is mainly determined by the size and the way of interaction between the internal forces and external forces in the growth field, and, at the same time, it will show the situation of motive force or resistance. Innovative teams in colleges and universities will experience several stages of learning, growth, maturity, and recession in the process of growth, and the intensity of their effects will also change due to the interaction of internal and external forces at each stage. Figure 2 shows the path of the overall innovation team.

Wang and $\mathrm{Yu}$ [41] studied the path of sustainable development of local university innovation teams; Qiu [42] researched the sustainable development path of university teachers' scientific research ability. Combining these studies, this article puts forward more novel ideas. From the perspective of the innovation team as a whole, it can be seen that, in the initial stage of the innovation team, the internal force plays a dominant role in the field and mainly supports the growth of innovation team. With the gradual growth of innovative teams in colleges and universities and the arrival of the second stage of rapid growth, the ability of individuals and the whole team as well as the number of output results will be significantly improved. The team as a whole mainly reflects the improvement of the overall ability and the increase of scientific research results, and the individual team has gradually changed from potential talents to prominent talents, which will be paid more attention or subsidized by the outside world, all of which constitute the driving force for the growth of innovation teams in colleges and universities. At the same time, resistance also exists. However, the power will be greater than the resistance, but, at this time, different levels of support are needed to promote its rapid growth into mature stage; the mature stage is the ideal stage; when the output increases significantly, the overall capacity of the team reaches its peak, and the field strength reaches its peak. However, the field strength will gradually weaken due to the accelerated reduction of some elements in the internal force. In order to avoid entering the recession prematurely, the external force should be increased to attract more and more talents to join so as to increase the internal motivation. On the basis of the accumulated experience and the continuous addition of talents, the innovation team can remain in the mature stage or move forward into a new round of continuous growth rather than entering a recession stage; in the recession stage, resistance is greater than internal force, growth is severely restricted, and even team disintegration occurs.

Team individuals are also in the process of growing up in the team as a whole. Different individual choices will lead to different individual development paths. Figure 3 is the growth path diagram at each growth stage from the perspective of individual members of an innovative team.

The internal and external forces in the growth field of university innovation teams are divided into different groups according to the size of the correlation under the influence of some factors. The motivation and resistance generated by different team members are also different. In Figure 3, only a few targeted elements of the internal and external environmental elements are listed. If the combined force of internal force and external force is motivation, which is greater than resistance in this field, it will move forward along the growth path; on the contrary, it will enter the recession or be stagnant in advance. 


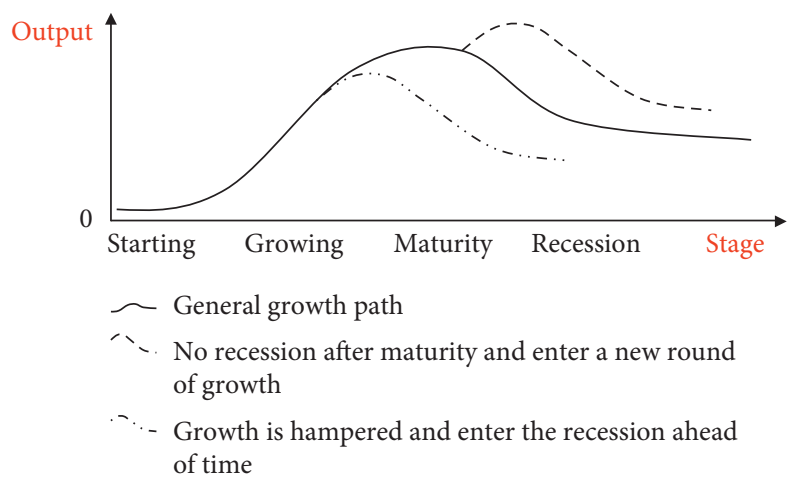

FIgURE 2: Growth path of colleges' and universities' innovation team.

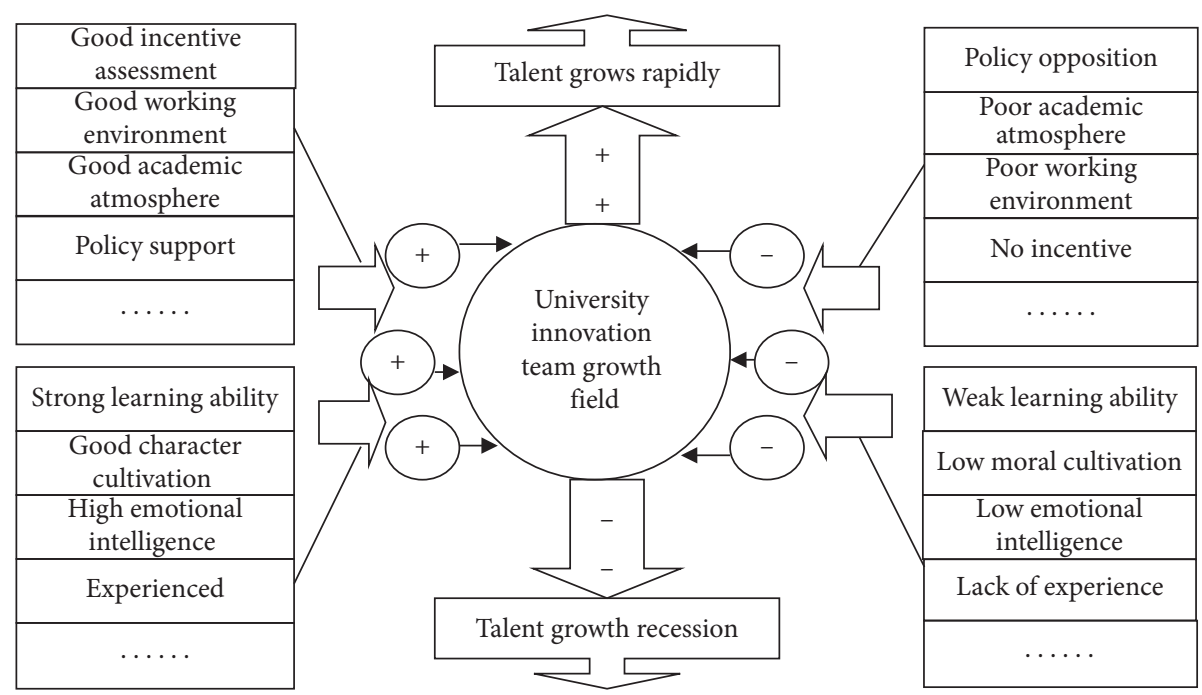

Representing power greater than resistance

Representing resistance greater than power

FIgURE 3: Impact of internal and external forces on the growth of team members.

4.3. The Agglomeration of Colleges' and Universities' Innovation Teams under the Field Effect. Wu et al. [43] studied the process of agglomeration of innovation factors in universities. Han [44] studied the relationship between technological talent gathering effect and innovation performance. There is also a phenomenon of agglomeration in the field; the process of forming the field force can be described as follows: first, there is a field around the excellent academic leaders and original resources; more and more excellent talents who study similar problems or have relevant research or are complementary to each other are attracted by the charm, knowledge, and so on, forming a situation of continuous gathering. This process is a process of overlapping forces; therefore, an excellent academic leader or "leader" of a team is very important to form the growth field of the colleges and universities innovation team. In addition, when the agglomeration effect of the innovation team is born, the new field power will come into being, which includes the internal forces of the integration of knowledge and ability within the innovation team and the external forces that influence the growth of the innovation team.

In Figure 4, there are two points, $\mathrm{A}$ and $\mathrm{B}$, which are regarded as two independent talents. Among them, A belongs to the edge of the field and $\mathrm{B}$ does not belong to the field. If the interaction between the internal and external elements is effective, the field strength is strong, and the field force is large; the edged A will be closer to the field source, and the offsite B can be attracted; on the contrary, if the field strength is weakened and the attraction to talents is reduced for some reason. It cannot attract member B to join, and it will cause member A to leave. In summary, it is necessary to increase the field strength continuously and then attract more and more excellent talents to join and form a "talent group." 
4.4. Integration and Ability Improvement of Colleges' and Universities' Innovation Teams under the Field Effect. Figure 5 shows the process of attracting and integrating the "growth field" of colleges' and universities' innovation teams to the off-site talents.

It can be seen from Figure 5 that the initial talent movement is disordered and finally becomes orderly. The "disordered movement" here shows that the goals and actions of independent individual talents are different. The "orderly movement" shows that, through the attraction and integration of talents in the growth field, each independent individual is integrated into a whole, and the goals and actions are systematic and orderly. The strong "growth field" of innovation team can attract outstanding talents who are scattered and disorderly off-site the field to join in and bring their relevant knowledge and skills into order state after the operation, integration, and promotion of relevant factors in the field. On the one hand, the field strength in the existing growth field is increased because of the participation of excellent talents. On the other hand, these external talents are transformed from "disordered movement" to "orderly movement." It is good for them to improve their comprehensive ability and enter a higher stage of growth. This creates an agglomeration effect that achieves the purposes of attracting talents, integrating talents, and increasing valueadding talent.

In this paper, $q_{i}$ represents the "charge amount" of the $i$ th member in the field. It describes the knowledge and skills of the individual and the whole innovation team through the agglomeration effect in the field. F describes the field force of the growth field so that the innovation team in the "growth field" is received by the electric field:

$$
\mathbf{F}=q_{i} \mathbf{E}
$$

This represents the most advantageous driving force for the growth of innovation teams. From the point of view of physics, for attracting more electrons outside the field and making the disordered motion orderly, it should try to increase the field strength. The way to increase the field strength is to increase the value of "Q," which is the field source, or decrease the value of "r," or both are performed simultaneously. Similarly, in order to attract more excellent talents, increase the field strength, enhance the innovation ability of team members, and increase the overall output, it should try to make the combination of internal and external elements become the driving force for the growth of innovation team, which needs to increase the incentives for the growth of innovation teams in the "growth field" and reduce the resistance of its adverse effects.

\subsection{Potential Application of the Growth Field of Colleges' and} Universities' Innovation Team. The paper introduces the growth field model of university innovation team to research the influence of various internal and external environments on the team in the process of formation, operation, and output of the university team. Based on this, choose the right time to provide targeted external force to the innovation team to achieve faster and better growth. The composition of the growth field of university innovation team is mainly composed of field source, internal force, and external force. The source of the growth field of university innovation team is the core element of the growth field and also the core input of innovation team, which determines whether it can develop and grow. It is mainly composed of team leaders and excellent team members with complementary advantages in disciplines and other fields, specifically including the knowledge and skills and outputs of existing members, especially the strength and influence of academic leaders, existing research infrastructure and funding, knowledge sharing platforms, the cooperation between university teams and high-tech enterprises, and the quantity and quality of innovation achievements, which constitute a growth field. The field source is also the motivation to attract outstanding talents to join, and the outputs of the results are constantly increasing; internal force is the internal synergy formed by the team members' age, physical and mental health, academic title, knowledge and skills, and other internal factors that affect team members' growth; external forces are external synergies formed by external factors such as living environment, policy environment, internal work and research environment of universities, management systems, and development plans in various places.

In theory, the development path of innovation team is similar to the curve of normal distribution, but, in fact, the growth path of each team is different, which mainly depends on the internal and external forces and the interaction between the teams in the process of growth. Take the team in the initial stage of construction as an example. This stage is mainly the new shaping stage of the growth field. At this time, the team's achievements are mainly the composition of team members, the original achievements, and scientific research facilities. However, due to the existence of Matthew effect, the attention of the team in the initial stage of growth will be limited, unless the research achievements of the academic leaders or some members of the team are significant or well known. At the same time, the motivation and resistance generated during the interaction of internal and external forces will also appear. If the external force has strong support or the internal force within the team is strong, that is, the motivation is greater than the resistance, then the team growth will smoothly enter the stage of growth and maturity not recession. On the contrary, if the resistance in the external force is too large, it is very difficult for the innovation team to enter the growth stage and directly enter the recession. At this time, it is necessary to increase the external force support to make it smoothly enter the rapid growth stage. The external support here requires the government, provinces, cities, and universities to provide corresponding policy support, funding support, management support, and other means to promote team growth. By studying the growth path, the stages of team development and the supports needed can be clearly understood.

The gathering and value-added of the growth field of university innovation team mainly refer to the fact that, under the action of a series of benign internal and external forces, the team members in the field are constantly enhancing knowledge sharing, the number of knowledge 

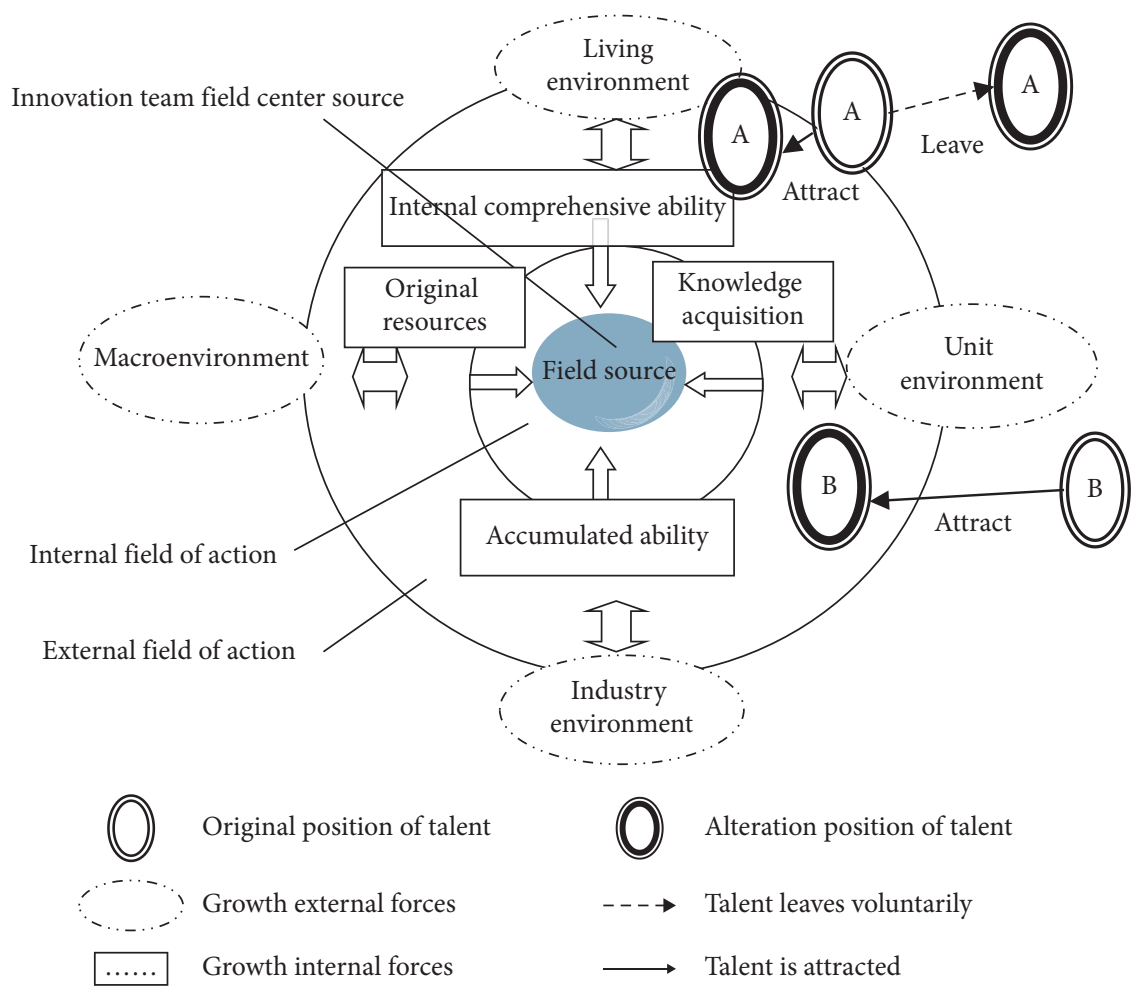

FIgURE 4: The agglomeration of colleges' and universities' innovation team.

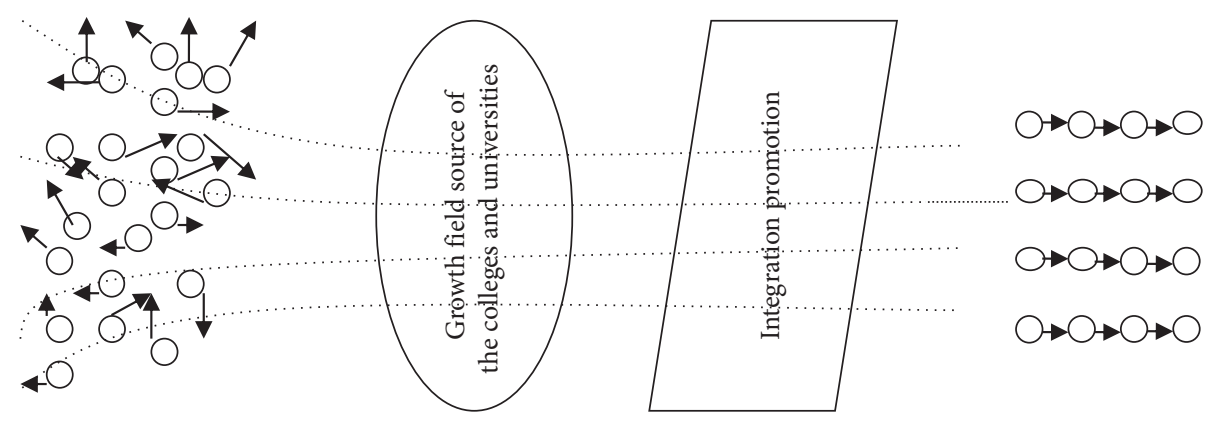

Attract talents

Integrate talents

Increase of value-added talents

Individual team members

$\rightarrow$ The goals and movement track of individual team members

FIgURE 5: Value-added process under the field effect of colleges' and universities' innovation team.

innovations and applications is increasing, and the overall team capacity and output are increasing. With continuous enhancement, the field source's attractiveness to external talents will gradually increase, which will attract more outstanding talents to join. New ideas and new knowledge brought by external outstanding talents will further promote knowledge sharing, effectively motivate internal members, and reach talent effective value-added, improve the overall innovation ability of the entire team, and thus achieve the purpose of increasing field strength, therefore forming a benign interaction cycle. The way to increase the field strength and attract talents to increase the value of talents can be supported by government and universities. By studying the agglomeration of growth fields, we can focus on the policy and effectively support the growth of innovative teams in universities.

The measurement of the effectiveness of the innovation team's growth field can be measured by the output of the university's innovation team. Li and Zhang [45] and other scholars studied the performance evaluation of scientific research teams. This article mainly measures the following team output indicators. First, the quantity and quality of scientific research results mainly include academic papers, books, and research reports, especially the key results, which should be especially valued. These key results should be the results of obvious innovations and breakthroughs in the theoretical or application fields jointly completed by team members. It can be evaluated from the perspectives of 
academic influence, socioeconomic benefits, innovation, and sustainable development by means of domestic and foreign expert evaluation. Second, regarding the quantity and quality of the awards, based on the principle of quality and systematic, they are divided into international award levels, national award levels, provincial and ministerial award levels, and school-level award levels according to their influence. Third, regarding the transformation and application of results, investigate the transformation and applicability of team results from the perspectives of solving social problems, solve business development problems, alleviate environmental problems, and support government decisionmaking. Fourth, for talent training, the assessment will be carried out in terms of improving the individual knowledge and skills of team members, promoting the growth of individual team members and the team as a whole, attracting outstanding talents to join, and training outstanding academic leaders.

Zhu [3], Qiu [42], and others studied strategies for the growth of innovative teams. Combining the research of scholars and this article, several suggestions are proposed to increase the boost and increase the field strength to promote the growth of innovative teams in universities.

4.5.1. Improve and Perfect the System and Policy of Talent Introduction and Create a Good Environment for Talent Introduction. The agglomeration effect of innovation teams is closely related to the talent introduction environment. Only a perfect talent introduction mechanism and talent incentive mechanism can provide a good environment for talent introduction, especially the introduction of team core talents. Therefore, a perfect normative system is the basis for the talent gathering of innovation teams. The more perfect the system, the more beneficial it is to attract talents and create a gathering effect. At the same time, it will create a strong atmosphere of innovation, increase innovation results, and enhance team competitiveness.

4.5.2. Implementing Incentive Measures at Different Stages. The leading role of internal and external influence elements of innovation teams in different growth cycles is different. Generally, in the growth stage, the internal elements play a leading role. The innovation team of colleges and universities in the growth stage and maturity stage is dominated by external elements. Therefore, we can refer to Maslow's hierarchy of demand theory to understand the level of innovation teams at different stages of growth and what motivating elements they need most at all levels and implement different incentive measures for innovation teams in different growth stages.

4.5.3. Pay Attention to the Role of Organizational Commitment, Improve the Loyalty of Innovative Teams in Colleges and Universities, and Reduce Instability. The innovation team in colleges and universities has some unstable factors, which will affect the team cooperation ability, knowledge sharing, and innovation ability of the whole team. The research shows that organizational commitment plays an important role in regulating the agglomeration effect of innovation team. Therefore, we should pay attention to the construction of organizational culture, increase the sense of belonging of university innovation team members to the organization, cultivate the loyalty of talents to the organization, and improve the stability of the team.

\subsubsection{Increase Funding and Education Investment to Provide} Sufficient Support for Team Innovation. In order to ensure that the innovation ability of the innovation team in colleges and universities is continuously improved and the innovation results are continuously enriched, sufficient funds and support from all sides are needed at every stage of the growth of the innovation team, but the focus of support is different at each stage. Innovative teams need to not only attract talents but also reeducate and retrain existing university innovation team members to enrich and update the knowledge reserves of current university innovation team members. Therefore, it is necessary to increase investment from various aspects such as funding and education to provide sufficient support for the team's scientific and technological innovation.

When applying the growth field model of university innovation team in practice, the above methods can enhance the field strength of the "growth field" of the innovation team in colleges and universities, help to attract talents to join, accelerate knowledge sharing, accelerate the improvement of the individual ability of the innovation team in this field, and enhance the overall ability of innovation team, which is conducive to produce more innovative results. This model has certain advantages as well as certain disadvantages, mainly due to its strong theory. It is difficult to grasp the timing and intensity of supporting the team's growth by increasing external forces, which requires further research in the future.

\section{Conclusion and Implications}

5.1. Conclusion. Based on literature research, this paper introduces "field theory" in the research process and compares the colleges' and universities' innovation team to a field and also compares the internal and external elements that influence the growth of the team to the internal and external forces in the growth field, as well as comparing the implicit relationship between the key elements affecting the growth of innovation teams to the field line. This paper constructs the growth field model of colleges' and universities, innovation team. The conclusions are as follows:

(1) Construct a field model for the growth field of colleges' and universities' innovation teams. The "growth field" of innovation teams is composed of two kinds of elements: "hidden growth elements" and "dominant growth elements." They are directional and forceful. The "dominant growth elements" can be regarded as the internal and external influence elements of the growth of the colleges' and universities' innovation teams, and the "hidden growth 
elements" can be regarded as the intangible effect formed by the interaction between these key elements. The internal and external forces that influence the growth of the innovation team in colleges and universities can be regarded as the internal and external growth elements. The internal and external forces in the growth field act together on the growth of innovation teams in colleges and universities. In order to achieve the rapid growth of the innovation team in colleges and universities, it is necessary to continuously integrate internal elements and actively strive for a good external environment. A person's influence is limited; the collective power is powerful and sometimes can even affect the external environment, but it is also affected by the external environmental elements. The increase of internal force will also affect the external force; when the internal force is increased to a certain extent, the resistance of the external force will become relatively weak, so that the motive force in the resultant force will increase. This will further promote the effective integration of internal resources of innovation teams in colleges and universities. In the process of mutual adjustment, the field strength increases, which is more conducive to the growth of the innovation team in colleges and universities, forming a virtuous cycle of interaction. That is, the internal force is decisive and the external force is influential.

(2) Research the growth path problem in the growth field. The growth path of the colleges' and universities' innovation team is mainly determined by the size and the way of interaction between the internal forces and external forces in the growth field, and, at the same time, it will show the situation of motive force or resistance. Innovative teams in colleges and universities will experience several stages of learning, growth, maturity, and recession in the process of growth, and the intensity of their effects will also change due to the interaction of internal and external forces at each stage. The internal and external forces in the growth field are divided into different groups according to the degree of correlation under the influence of some elements. However, due to the different intrinsic quality and external environment of each colleges and universities innovation team member, these elements have different motivation and resistance to different team members. If the combined force of internal force and external force is motivation, which is greater than resistance in this field, it will move forward along the growth path; on the contrary, it will enter the recession or be stagnant in advance. Liang et al. [4] believe that the magnitude and direction of the forces received at each stage are different and the growth path of individual team members is different from that of the whole team.

(3) Research the phenomenon of agglomeration of innovation teams under the effect of "field." Han [44] believes that there is a gathering of scientific and technological talents. There is also a phenomenon of agglomeration in the field. First, there is a field around the excellent academic leaders and original resources; more and more excellent talents are attracted, forming a situation of continuous gathering. This process is a process of overlapping forces; therefore, an excellent academic leader or "leader" of a team is very important to form the growth field of the colleges' and universities' innovation team. In addition, when the agglomeration effect of the innovation team is born, the new field power will come into being, which includes the internal forces of the integration of knowledge and ability within the innovation team and the external forces that influence the growth of the innovation team.

(4) The integration and ability improvement of colleges' and universities' innovation teams under the field effect. A strong "growth field" of innovation team can attract outstanding talents who are scattered and disorderly off-site the field to join in and bring their relevant knowledge and skills into order state after the operation, integration, and promotion of relevant factors in the field.

(5) The potential applications of the growth field of university innovation teams are studied. It expounds the composition of the growth field of university innovation team, the growth path of the innovation team after its formation, the concentration and value-added of the growth field of university innovation team, and the measurement of the effectiveness of the growth field of university innovation team and puts forward several suggestions to increase the boost and increase the field strength to promote the growth of college innovation teams.

5.2. Suggestions for Future Research. This paper introduces the field theory in the research and draws relevant conclusions. However, there are still some shortcomings, and many problems need further study.

(1) The research on the growth field of colleges' and universities' innovation teams needs to be further studied. This paper introduces field thinking into the process of the growth of innovation teams, but due to the limitation of objective resources, there is no more in-depth quantitative research, which needs to be studied.

(2) The research on the growth path is not deep enough. In this paper, the growth path of individual team members and the whole team has been preliminarily studied in the process of research, but no further research has been carried out, which needs to be improved.

\section{Data Availability}

All data, models, and codes generated or used during the study are included within the article. 


\section{Conflicts of Interest}

The authors declare no conflicts of interest.

\section{Acknowledgments}

This research was supported by the Nanjing Institute of Technology Youth Science Fund Project, "Research on the Mechanism and Incentive Mechanism of Colleges and Universities Innovation Teams in Jiangsu Province," (no. QKJ 201706); Natural Science Foundation of Jiangsu Province (no. BK20160772); Scientific Research Fund Project of Nanjing Institute of Technology: Research on China's Ecological Welfare Performance Evaluation and Improvement Path from the Perspective of High Quality Development (no. CKJA201905); and Scientific Foundation of Nanjing Institute of Technology (nos. YKJ201538 and JCYJ201620).

\section{References}

[1] N. S. Zou and J. L. Wei, "Research on the status and strategy of building an innovation-oriented university research team," Technology and Innovation Management, vol. 35, no. 5, pp. 417-421, 2014.

[2] S. Q. Fu, "Research on China's central government's university research funding policy since reform and opening," Higher Education Exploration, vol. 5, pp. 24-28, 2013.

[3] J. K. Zhu, Research on Incentive Mechanism of Scientific Research Innovation Team in Colleges and Universities, China University of Mining and Technology, Xuzhou, China, 2018.

[4] H. J. Liang, Y. Y. Zhou, and Y. Q. Song, "Construction of colleges and universities innovation team under the "field" effect," Journal of Nanjing Institute of Technology (Social Science Edition), vol. 19, no. 1, pp. 56-60, 2019.

[5] E. Sundstorm, M. K. De, and D. Ferrell, "Work teams: applications and effectiveness," American Psychologist, vol. 45, no. 2, pp. 120-133, 1990.

[6] K. Zhang, "Performance analysis of information field," Journal of Intelligence, vol. 22, no. 2, pp. 19-20, 2003.

[7] S. P. Robbins, Organizational Behavior, Renmin University of China Press, Beijing, China, 1997.

[8] M. Hoegl and H. G. Gemuenden, "Teamwork quality and the success of innovative projects: a theoretical concept and empirical evidence," Organization Science, vol. 12, no. 4, pp. 435-449, 2001.

[9] A. Drach-Zahavy and A. Freund, "Team effectiveness under stress: a structural contingency approach," Journal of Organizational Behavior, vol. 28, no. 4, pp. 423-450, 2007.

[10] G. M. Paker, Team Players and Teamwork: The New Comptitive Business Strategy, Jossey-Bass Inc, San Francisco, CA, USA, 1990.

[11] J. Rey-Rocha, M. J. Martín-Sempere, and B. Garzón, "Research productivity of scientists in consolidated vs. nonconsolidated teams: the case of Spanish university oeologists," Scientometrics, vol. 55, no. 1, pp. 137-156, 2002.

[12] B. Nijstad, Team Creativity and Innovation: A Motivated Information Processing Perspective, Erasmus Research Institute of Management, Rotterdam, Netherlands, 2018.

[13] X. C. Wang and J. L. Tian, Research on the Construction of Scientific Research Teams in Local Universities, vol. 6, Chinese University Science \& Technology, Hefei, China, 2014.
[14] C. Zhang, L. H. Zhu, and L. S. Yang, "Interactive innovation of knowledge service for university research teams," Research in Higher Education of Engineering, vol. 5, pp. 164-168, 2017.

[15] C. J. Zhou, Discussion on the Construction of Incentive Mechanism of Innovation Team, Chinese University Science \& Technology, Hefei, China, 2015.

[16] M. L. Zhang, "On college research teams building in the innovation context," Huazhong Normal University, Wuhan, China, Doctorial dissertation, 2011.

[17] W. Yuan, How to Construct the Incentive Mechanism ofScientific Research Innovation Team in Colleges and Universities,vol. 8, Chinese University Science \& Technology, Hef, china, 2015.

[18] Q. Y. Zhang, "Strategies for improving the innovation ability of scientific research teams in colleges and universities," Journal of Yanbian Party School, vol. 31, no. 1, 2015.

[19] J. B. Clark, “The moral outcome of labor troubles," The New Englander, Yale Review, vol. 195, pp. 533-536, 1886.

[20] F. Sahin, "Manufacturing competitiveness: different systems to achieve the same results," Production and Inventory Management Journal, vol. 41, no. 1, pp. 56-64, 2000.

[21] M. Giannetti, "Skill complementarities and migration decisions," Labour, vol. 15, no. 1, pp. 1-31, 2001.

[22] B. Venkatesh and S. Gerhard, "A spatial-temporal model of human capital accumulation," Journal of Economic Theory, vol. 96, no. 1-2, pp. 153-179, 2009.

[23] P. Romer, "Endogenous technological change," Journal of Political Economy, vol. 98, no. 5, 2007.

[24] C. Freeman, Technology Policy and Economic Performance: Lessons from Japan, Pinter Publishers, London, UK, 2007.

[25] C. H. Niu, "Analysis and countermeasures of talent accumulation phenomenon and talent accumulation effect," Journal of Shandong University of Science and Technology (Social Sciences), vol. 8, no. 3, pp. 13-17, 2006.

[26] L. Y. Wang, Research on the Agglomeration Mode of Innovation and Entrepreneurship Talents in Baotou City, Inner Mongolia University of Science \& Technology, Baotou, China, 2017.

[27] M. H. Chen, "Research on the effect and strategy of talent agglomeration needed by entrepreneurial innovation," Journal of Commercial Economics, vol. 1, pp. 131-133, 2017.

[28] W. C. Wang, "Research on the "trinity" talent agglomeration model of Zheng Luoxin national independent innovation demonstration zone," The Forum of Leadership Science, vol. 11, pp. 24-25, 2017.

[29] E. G. Ravenstein, "The laws of migration," Journal of the Statistical Society of London, vol. 48, no. 2, pp. 167-235, 1985.

[30] W. J. Reilly, The Law of Retail Gravitation, Knickerbocker Press, New Rochelle, NY, USA, 1931.

[31] S. Smith, L. Y. Zhang, and X. Z. Li, "Application of gravitational model in tourism geography," Geographical Translation, vol. 7, no. 3, pp. 51-55, 1988.

[32] G. X. Wang, "Ecological field theory," Progress in Geography, vol. 8, no. 6, pp. 76-78, 1993.

[33] Y. Dong and G. D. Xie, "Pilot study of resources field theory and its application to resources flow," Scientia Geographica Sinica, vol. 21, no. 5, pp. 24-28, 2001.

[34] J. H. Zhang, J. Zhang, and Z. H. Liu, "A study on spatial competition among tourism regions based on the theory of tourism field," Scientia Geographica Sinica, vol. 25, no. 2, pp. 248-256, 2005.

[35] X. G. Xu, B. Q. Mei, and Y. W. Wu, "Study on spatial knowledge radiate effects of knowledge field based on knowledge attributes and field theory: taking the Yangtze river 
delta as an example," Science \& Technology Progress and Policy, vol. 2, pp. 142-147, 2016.

[36] S. Chen, J. Liu, and H. Wang, "Initial research on the theory and application of urban water demand field," Chinese Science Bulletin, vol. 61, no. 13, pp. 1428-1435, 2016.

[37] G. H. Ma, Field Theory, Atomic Energy Press, Beijing, China, 1st edition, 1995.

[38] R. Xing, The Relationship between Growth Elements and Growth Path of Start-Up Technology SMEs, Dalian University of Technology, Dalian, China, 2007.

[39] L. Y. Tang, G. H. Wang, and R. Xing, "Research on the growth of technological SMEs based on the "growth ba"' Journal of Dalian University of Technology (Social Sciences), vol. 2, pp. 30-33, 2007.

[40] T. X. Wang, "Eight rules of talent growth," Decision \& Information, vol. 13, no. 5, pp. 15-16, 2006.

[41] Y. X. Wang and L. J. Yu, "Research on the sustainable development path of innovation team in local colleges and Universities," Science and Technology Innovation Herald, vol. 12, no. 17, p. 197, 2015.

[42] C. Qiu, "On the sustainable development path of University teachers' scientific research ability," Management Observer, vol. 599, no. 36, pp. 135-137, 2015.

[43] W. H. Wu, T. Yang, and A. M. Zhang, "Study on spillover effects of universities'innovation resources gather on regional innovation efficiency," Science \& Technology Progress and Policy, vol. 11, 2018.

[44] F. Han, On the Relationship between Technological Talents Agglomeration Effect and Innovation Performance: Organizational Commitment as a Moderator, Shandong University of Finance and Economics, Jinan, China, 2015.

[45] Z. Li and T. Q. Zhang, "Performance evaluation index system for academic innovation team of humanity and social science in universities based on IMO model," Journal of Chongqing University (Social Science Edition), vol. 24, no. 2, pp. 77-86, 2018. 